\begin{tabular}{cc}
\hline Markmals & INDUSTRIAL \\
RESEARCH & MANAGEMENT \\
\hline
\end{tabular}

\title{
The effect of real exchange rate on unemployment
}

\author{
Zahra Bakhshi*, Mehrzad Ebrahimi \\ Shiraz Branch, Islamic Azad University, Shiraz, Iran
}

\begin{tabular}{ll}
\hline & ABSTRACT \\
\cline { 2 - 3 } & $\begin{array}{l}\text { Unemployment is one of the problems that global economics, especially the economy of } \\
\text { developing countries such as Iran is faced with. Therefore, there have been many studies to } \\
\text { investigate the variables which affect unemployment in macroeconomics. Considering } \\
\text { Keywords: }\end{array}$ exchange rate volatility in recent years which have affected most of major variables of \\
Unemployment Rate, & economy in Iran, this study tried to investigate the relationship between exchange rate and \\
Exchange Rate Volatility, & unemployment in Iran using the annual data of 30 years (from 1981 to 2012). To achieve the \\
Export, Import, Gross & objectives of the study, autoregressive econometric model with distributed lag was used to \\
Domestic Product & assess the relationship between real exchange rate and unemployment. This model consisted \\
& of five main variables, namely unemployment rate, exchange rate, export, import, and gross \\
domestic product. The results of the study demonstrated that economic growth had a & significant and positive effect on unemployment. In addition, it was shown that there was a \\
negative relationship between unemployment and exchange rate.
\end{tabular}

(C)AIMI Journals

\section{Introduction}

Nowadays, unemployment is a big problem in developing countries including Iran. The only thing which can improve poor economic conditions in these societies is the active economy which can affect the growth of economy in various ways. The problems caused by unemployment are more tangible in countries which have a younger population, especially in countries that have not basically predicted the issues related to social and economic structures with necessary and timely investments. It should be mentioned that in countries such as Iran, in which the main part of governmental income is from foreign exchange earnings through exporting mineral material, exchange rate is one of the important variables in economic system. 
On the other hand, exchange rate volatility has caused widespread changes in the economy of developing countries. Although exchange rate volatility may be necessary for getting stability in macroeconomics in long term, instability of exchange rate has theoretically negative effects on economy in short term. Therefore, as a kind of risk factor, exchange rate volatility should be studied more closely because these fluctuations can cause risk-averse investors that have less investment, and as a result it would cause a reduction in the employment rate (De Grauwe, 1988).

Considering the fact that labor market is interrelated to other economic markets, it is mentioned as an important market in economy (Azvaji \& Asgari, 2005). In Iran, labor market has been faced with the increase of unemployment because of a number of reasons such as drastic growth of population in the early years after revolution, inability of government to create required number of job opportunities, economic sanction, and obstacles to the import of machinery for building factories. This means that during recent years labor supply has exceeded labor demand and this excess has increased gradually and caused unemployment and lack of suitable job for the work force, especially for young people and university graduates.

Employment of human work force is an important issue which is related to many factors. On the one hand, labor supply is related to some variables including population growth, age and population distribution, emigration, and women's participation rate. On the other hand, labor demand is related to a number of variables such as the volume of investment, distribution of investment, technology, and economic growth.

Although exchange rate has always been of great importance and sensitiveness, the sensitivity of the issue increases when it is determined incorrectly (Mohammadi \& Masjedi, 1997). Therefore, the policy for determining exchange rate is a sensitive issue and while determining exchange rate any types of mistake should be avoided. Theoretically speaking, export is a function of the level of domestic prices, exchange rate, and production. Considering the fact that changes in exchange rate can cause changes in the amount of export and import and as a result in the amount of production, if the increase of exchange rate (i.e. devaluation) increases the price of imports, the amount of imports will decrease and domestic products will replace imports and in turn, this will increase employment, develop industry, and expand factories to employ more work force (Gharavi Nakhjavani, 2002).

However, the decrease of the price of exports can make an attraction for the foreign market and it can increase the competitive ability of country and, as a result, it would increase the amount of export. Thus, the amount of demand in the country increases and with the stability of other conditions and the attraction of supply, it results in the increase of domestic production. The increase of exports results in the increase of production and this increases the demand for work force and, as a consequence, it has positive effects on employment. Some other factors such as labor productivity, gross domestic product, real interest rate, and inflation have some positive or negative effects on unemployment. Due to this, it can be stated that increase or decrease of exchange rate has some effects on unemployment.

In this study, according to the fact that in recent years exchange rate has been one of the most important and effective variables in employment or unemployment in Iranian economy, its effect on unemployment has been investigated. 


\section{The Literature Review}

In the history of studies about the relationship between exchange rate and unemployment, there have been some controversies. On the one hand, some studies tried to investigate if there are any relationships between them or not. On the other hand some studies, hypothesizing that there are some kind of relationship between them, aimed to understand the nature of this relationship. Trying to achieve this enterprise, some researchers stated that the relationship between them is negative while others asserted a positive relationship.

First of all, Milas and Legrenzi (2006), Frenkel and Ros (2006), Djivre and Ribon (2000), Chang (2011), Nyahokwe and Ncwadi (2013), Shaari, Hussain, and Abdul Rahim (2013), and Mohammadi and Gholami (2008) tried to find out whether there were any relationships between exchange rate and unemployment. They all approved the existence of this relationship except Mohammadi and Gholami (2008) that rejected the existence of such relationship.

Milas and Legrenzi (2006) used UK data from 1973 to 2004 and established that the dynamics of the real exchange rate, real wages, and unemployment varied both with large versus small real exchange rate disequilibria and rising versus falling unemployment regimes. They also stated that unemployment reduced because of earnings in competitiveness when the real exchange rate was further away from equilibrium.

Frenkel and Ros (2006) investigated the role of the real exchange rate in the recent unemployment performance of Latin American countries such as Argentina, Brazil, Chile, and Mexico. Empirical evidence from their study indicated that the hypothesis of an important influence of the real exchange rate on unemployment cannot be rejected.

Djivre and Ribon (2000) examined the Israeli economy during the years 1990-1999 and found that positive shocks to the interest rate slowed down inflation and were reflected in arise in the ex-post real interest rate and in unemployment. The inflation response to interest rate shocks was rather fast as a result of the exchange rate response to the changes in the interest rate.

Chang (2011) estimated the effect between exchange-rate uncertainty and unemployment in South Korea and Taiwan and found that a long-run equilibrium relationship between exchange-rate uncertainty and unemployment existed in both Taiwan and South Korea when exchange-rate uncertainty was generated by two different measures. They also expressed that exchange-rate uncertainly had a short-run effect on unemployment and vice versa, no matter which measure of uncertainty was utilized.

Nyahokwe and Ncwadi (2013) investigated the impact of real exchange rate volatility on unemployment in South Africa. The most interesting result that emerged from their study was that among other determinants, real exchange rate explained the largest proportion of the variation in unemployment rate. On balance, the evidence proposed that unemployment rate fluctuations were mainly equilibrium responses to real exchange rate shocks in comparison with interest rates, economic growth, and exports.

Shaari et al. (2013) tried to investigate the impacts of oil price and exchange rate on unemployment in Malaysia. The effort to find long run relationship between exchange rate, oil price, and unemployment resulted in the confirmation of such a relationship. The examinations to find short run relationship gave the result that short run relationships were 
influenced by the estimated long run equilibrium and that oil price did not affect unemployment but exchange rate had an influence on unemployment. Therefore, they concluded that putting the exchange rate under control had to be implemented to control unemployment.

However, contrary to all these studies, the study done by Mohammadi and Gholami (2008) in Iran indicated that the official exchange rate had no significant relationship with real gross domestic product and unemployment rate.

Following this, some studies tried to get to the essence of the relationship between real exchange rate and unemployment. Ranjbar and Moazen (2009), Behnamian (2012), Frenkel (2004), and He (2013) predicted negative relationship between these two variables of economy. However, Lindblad and Sellin (2008), Feldmann (2011), Chimanani, Bhutto, Butt, Sheikh, and Devi (2012), and Zhou (2010) assumed positive relationship between exchange rate and unemployment.

Ranjbar and Moazen (2009) investigated the factors affecting unemployment in eight countries of the Organization of Islamic Cooperation (OIC), namely Iran, Egypt, Indonesia, Kazakhstan, Malaysia, Morocco, Pakistan, and Turkey using the data of 7 years from 1999 to 2006. The results of their study demonstrated that unemployment had an indirect and negative relationship with gross domestic product, industrial export, and real exchange rate and it had a direct and positive relationship with the size of workforce.

Behnamian (2012) examined the long run relationship between real exchange rate and unemployment in the economy of Iran between the years 1962 and 2010. He concluded that real exchange rate had negative effect on employment during this period.

Frenkel (2004) discussed the mechanisms by which real exchange rate affected the employment performance. He distinguished three channels including macroeconomic channel, development channel, and labor intensity channel. The first channel pointed to the role of real exchange rate in the determination of the activity and employment levels in the short run. The second one pointed to the influence of real exchange rate on economic growth and consequently, on the speed of generation of new jobs. Finally, the third channel focused on the role of real exchange rate in affecting the labor intensity of the economic process; that is, the influence of real exchange rate on the employment generation ability of a given activity level or rate of output growth. Therefore, all these factors had positive effects on employment and as a consequence, it had negative effect on unemployment. Later in his study, Frenkel presented stylized facts and empirical results about the relationship between real exchange rate and the employment performances in Argentina, Brazil, Chile, and Mexico.

He (2013) examined the relationship between unemployment rate and real effective exchange rate in several countries from 1994 to 2009. The analysis showed that most of the countries demonstrated a negative relationship between those two factors which implied that increase of exchange rate could improve employment rate in an economy. Hence, reexporting countries like the Netherlands, Singapore, and Hong Kong had a less negative relationship than other countries. He hypothesized that those results were caused by the different elasticity of demand for imports. 
Therefore, some researchers found positive relationship between real exchange rate and unemployment. Lindblad and Sellin (2008) set up and evaluated a structural unobserved components open economy model for the unemployment rate and the real exchange rate. This approach empowered them to simultaneously determine changes in both cyclical and equilibrium rates in these two variables. The findings demonstrated that the considerable changes in the Swedish unemployment rate during the 1990s were largely a cyclical phenomenon. The development of the exchange rate was predominantly driven by terms of trade and government deficits. Therefore, the development of the Swedish unemployment rate was successfully explained by the depreciation of the real exchange rate, a higher replacement ratio, and higher taxes.

Feldmann (2011) used the data on 17 industrial countries from 1982 to 2003 and controlled for a wide array of factors to get only the effect of exchange rate volatility on unemployment. He found that higher exchange rate volatility increased unemployment rate. However, the magnitude of the effect was small.

Chimanani et al. (2012) studied the effect of exchange rate on unemployment rate in ten Asian countries including Pakistan, India, China, Japan, Bangladesh, Argentina, Algeria, Brazil, Colombia, and Sri Lanka using unbalanced panel dataset from the period of 1995 to 2005. The finding of study indicated that exchange rate volatility had positive and significant effect on unemployment rate in Asian countries.

Finally, Zhou (2010) tried to establish a simple theoretical relationship between exchange rate and unemployment. He made a conclusion that the impact of exchange rate was unconditional in that home currency depreciation assisted employment and alleviated the unemployment problem.

\section{Method}

In this study the annual data related to exchange rate and unemployment rate of the years between 1981 and 2012 were gathered and analyzed to detect the kind of relationship between these two variables. In addition, to achieve the purpose of the study, Pesaran, Schuermann, Treutler, and Weiner (2006) model was applied to estimate the effect of exchange rate on unemployment. Therefore, the following equation obtained from Pesaran et al. model for the relationship between exchange rate and unemployment was of help:

$$
\begin{aligned}
& \ln u=\alpha_{1}+\sum_{i=1}^{p} \beta_{1} \ln U_{t-i}+\sum_{i=0}^{p} \beta_{2} \ln R E R_{t-i}+\sum_{i=0}^{p} \beta_{3} \ln G D P_{t-i}+\sum_{i=0}^{p} \beta_{4} \ln E X_{t-i}+\sum_{i=0}^{p} \beta_{5} \ln I M_{t-i} \\
& \delta_{1} \ln U_{t-1}+\delta_{2} \ln R E R_{t-1}+\delta_{3} G D P_{t-1}+\delta_{4} \ln E X_{t-1}+\delta_{5} \ln I M_{t-1} \\
& \mathrm{U}=\text { unemployment rate } \\
& \text { RER = real exchange rate } \\
& \text { GDP = gross domestic product } \\
& \mathrm{EX}=\text { export } \\
& \mathrm{IM}=\text { import }
\end{aligned}
$$




\section{Results}

Autoregressive Distributed Lag (ARDL) model which was used for the analysis of the relations was estimated using Microfit 4.1 software in the current study. Therefore, using the data for unemployment and exchange rate in the years between 1982 and 2012 (i.e. 30 years), lag 1 was considered as the maximum lag. In the annual data, the lag is considered to be 1 or 2 and for data with higher frequency (e.g., quarterly or monthly data), the lag length can even be selected higher and this depends on the researcher's decision. After choosing the maximum lag, the optimal lag length was selected using Schwarz Bayesian Information Criterion (BIC) from among other criteria such as Akaike information criterion (AIC), Hannan-Quinn information criterion, and adjusted coefficient of determination. Schwarz Bayesian Information Criterion is usually used in samples smaller than 100 to prevent losing degree of freedom. The maximum lag of the model was selected to be 1 and the software of Microfit 4.1 chose ARDL $(1,0)$ as the best model according to Schwarz Bayesian Information Criterion. The results of the estimation of the Autoregressive Distributed Lag model are presented in Table 1 .

Table 1

The Results of the Estimation of ARDL Model

\begin{tabular}{cccc}
\hline Variable & Coefficient & SD & Sig. \\
\hline U (-1) & .48 & .1634 & .0016 \\
GDP & .18 & .065 & .017 \\
RER & -.032 & .017 & .070 \\
Export & -.044 & .085 & .604 \\
Import & -.3151 & .966 & .747 \\
\hline
\end{tabular}

Note. ARDL = Autoregressive Distributed Lag model; U = Unemployment; $\mathrm{GDP}=$ gross domestic product; RER = Real Exchange Rate; Sig. = calculated statistical significance

Short-run results of the study presented in Table 1 demonstrated that economic growth had positive and significant effect on the increase of unemployment but the relationship between exchange rate and unemployment was reverse with a coefficient of -.032 which indicated negative effect of exchange rate on unemployment. Following this, export and import had no significant effect on unemployment.

After determining optimal lag length and doing short-run test, bound test was done to determine whether there were any long-run relationships between exchange rate and unemployment. The data related to the bound test is presented in Table 2. In bound test, F statistic has to be compared to the bounds presented by Pesaran, Shin, and Smith (2001). If calculated F statistic is higher than lower and upper bounds of Pesaran et al., then the existence of a long-run relationship between variables can be proved.

Table 2

Bound Test

$\begin{array}{cc}\text { Calculated F } & 8.48 \\ \text { Lower bound } & 4.36 \\ \text { Upper bound } & 5.88 \\ \text { of explanatory variables } & 4\end{array}$


According to Table 2, the calculated F statistic for lag 1 with $\alpha$ level of .05 was higher than upper bound presented by Pesaran et al. (2001); therefore, the null hypothesis of lack of long-run relationship was rejected. As a result, it could be asserted that the variables of the study were correlated and there was a long-run relationship between them. After the confirmation of long-run relationship, the kind of relationship between variables was determined; in other words, it was determined if the relationship between variables was negative or positive. The data related to the kind of relationship is presented in Table 3.

Table 3

Estimation of Long-run Relationship

\begin{tabular}{ccccc}
\hline Variable & Coefficient & SD & $\mathrm{t}$ & Sig. \\
\hline GDP & .35311 & .11297 & 3.1258 & 4.0 \\
RER & -.064060 & .28112 & -2.2787 & .0311 \\
Export & -.087420 & .16206 & -.53944 & .5941 \\
Import & -.061534 & .19402 & -.317161 & .7541 \\
\hline
\end{tabular}

Note. GDP = gross domestic product; RER = Real Exchange Rate; Sig. = calculated statistical significance.

According to the results presented in Table 3, it can be stated that in long run, gross domestic product had a positive and significant effect on unemployment. However, there was a negative and significant relationship between exchange rate and unemployment and there was no significant relationship between unemployment and other variables, that is export and import.

After the estimation of long-run relationship, Error Correction Model was used to investigate the relationship between short-run fluctuations and equilibrium values of long-run model. The statistics related to Error Correction Model is illustrated in Table 4.

Table 4

Error Correction Model

\begin{tabular}{ccccc}
\hline Variable & Coefficient & SD & $\mathrm{t}$ & Sig. \\
\hline GDP & .20859 & .068585 & 3.0413 & .006 \\
RER & .047581 & .0021159 & -2.2487 & .034 \\
Export & .024678 & .10212 & .24104 & .812 \\
Import & -.10439 & .17803 & .92024 & .367 \\
ECM $(-1)$ & -.60052 & .04439 & -3.3732 & .0031 \\
\hline
\end{tabular}

Note. GDP = gross domestic product; RER = Real Exchange Rate; ECM = Error Correction Model; Sig. = calculated statistical significance.

The results presented in Table 4 indicated that the coefficient of Error Correction Model was negative and significant with $\alpha$ level of .05. In addition, other calculated coefficients of the model were not rejected with significant level of $90 \%$; following this, the estimation of adjustment factor showed that 60 percent of lack of equilibrium was adjusted every year.

However, before concluding about any of the results of study, it was necessary to be sure of the assumptions of classical regression. Therefore, the existence of these assumptions was assured using the test of No Heteroskedactisity, Normality Test of Residuals, Specification Test of Functional Form, and test of No Auto-correlation. The statistics related to these tests are presented in Table 5. 
Table 5

Assumptions of Classical Regression

\begin{tabular}{ccccc}
\hline & HET & NORM & FUNC & COREL \\
\hline LM & 6.32 & .1948 & .5796 & 2.701 \\
PROB & .708 & .907 & .4466 & 01001 \\
\hline
\end{tabular}

Note . HET = No Heteroskedactisity; NORM = Normality Test of Residuals; FUNC = Specification Test of Functional Form; COREL = No Auto-correlation.

According to the results of diagnostic tests given in Table 5, it was demonstrated that the assumptions of No Heteroskedactisity, Normality of Residuals, Specification of Functional Form of model, and No Auto-correlation were confirmed.

\section{Discussion}

Exchange rate is one of the important variables which affect unemployment in Iran. Real exchange rate volatility results in the fluctuations of the real value of domestic currency, and consequently cause changes in the level of product and employment. The results of the stability of variables showed that the variables of study were of I (1) and I (0); therefore, the model of autoregressive distributed lag was used to assess the relationship between variables, and the optimal lag length was determined. Optimal lag for unemployment rate, gross domestic product, exchange rate, export, and import was specified using Schwarz Bayesian Information Criterion (BIC) or Akaike Information Criterion (AIC) and the best optimal lag was determined to be 1 . Before discussion about the results of the study the assumptions of classical regression were verified using the test of No Heteroskedactisity, Normality Test of Residuals, Specification Test of Functional Form, and No Auto-correlation, and all regression assumptions were verified. Then, the results of the study were analyzed. Short-run results indicated that there was a positive and significant relationship between economic growth and unemployment and a negative and significant relationship between exchange rate and unemployment with a coefficient of -.032. However, export and import had no significant effect on unemployment. After the analysis of short-run relationship, long-run relationship was checked using bound test. According to the bound test, the calculated F statistic was higher than the upper bound presented by Pesaran et al. (2001). Therefore, the null hypothesis of lack of long-run relationship was rejected in favor of the alternative hypothesis and it could be stated that there was a significant long-run correlation between the variables of study. In long-run, the coefficient of exchange rate was -.064 which indicated that exchange rate had negative effects on unemployment in Iran. These results verified the findings of Ranjbar and Moazen (2009), Behnamian (2012), Frenkel (2004), and He (2013) who stated that it was not possible to reject the negative effects of real exchange rate on unemployment. However, these results were contrary to the findings of Lindblad and Sellin (2008), Feldmann (2011), Chimnani et al. (2005), and Zhou (2010) who stated that exchange rate had positive effect on unemployment rate. On the other hand, the findings of the present study verified Chang (2011) and Nyahokwe and Ncwadi's (2013) findings claiming the presence of a longrun relationship between unemployment and exchange rate.

The coefficient of gross domestic product was .035 and as a result it had a direct relationship with unemployment in Iran. Other variables such as export and import had no 
significant effect on unemployment. The results of the estimation of Error Correction Model showed that the coefficient of ECM was negative and it was significant with $\alpha$ level of .05 . In addition, other coefficients of the model were not rejected with statistical significance of $90 \%$; therefore, estimation of adjustment factor indicated that every year $3 \%$ lack of equilibrium was adjusted. After the analysis of the findings of study, the stability of the coefficients of the model was assessed using the tests of CUSUM and CUSUMQ which have been used in econometrics for a long time. In these tests, the null hypothesis assessed the stability of parameters with a significance level of .05 . The results of these tests verified the stability of coefficients in significance level of .05. In other words, the null hypothesis of the stability of coefficients was not rejected with a confidence level of $95 \%$.

\section{Conclusion}

The emergence of mass unemployment in many countries including Iran can have a variety of causes. In the present study, four variables, namely exchange rate volatility, export, import, and gross domestic product which could have some effects on unemployment were examined. Using Autoregressive Distributed Lag model with five variables of unemployment rate, exchange rate volatility, export, import, and gross domestic product, the results of study demonstrated that in both short run and long run, gross domestic product had a positive and significant effect on unemployment and exchange rate had a negative and significant effect on unemployment and there was no significant relationship between unemployment and other variables of study including export and import.

However, this study suffered from a number of limitations. Many other factors which could have vital effects on unemployment were not examined in this research. In addition, the direction of the effect of real exchange rate on unemployment was not assessed; that is, it was not examined whether exchange rate had direct or indirect effect on unemployment. If it had an indirect effect, it meant that exchange rate affected other factors and then other factors affected unemployment. However, the findings of this study can be used in many ways to alleviate the unemployment problem.

\section{References}

Azvaji, A., \& Asgari, M. (2005). Evaluation of the factors affecting employment growth in regional and trade unions and political advice for the Iranian labor market. Growth \& Sustainable Development Research, 18, 21-50.

Behnamian, M. (2012). Effects of real exchange rate on unemployment in Iran. Economic Journal: Bimonthly of Investigation into Economic Policies and Affairs, 11/12, 23-40.

Chang, S. C. (2011). The interrelationship between exchange-rate uncertainty and unemployment for South Korea and Taiwan: Evidence from a vector autoregressive approach. International Economics, 125, 65-82.

Chimanani, H., Bhutto, N. A., Butt, F., Sheikh, S. A., \& Devi, W. (2012). The effect of exchange rate on unemployment rate in Asian countries. Proceedings of 2nd International Conference on Business Management.

De Grauwe, P. (1988). Exchange-rate variability and the slowdown in growth of international trade. IMF Staff Papers, 35, 63-84.

Djivre, J. \& Ribon, S. (2000, June). Inflation, unemployment, the Exchange Rate and Monetary Policy in Israel 1990-1999: A SVAR Approach. Paper presented at the meeting of Bank of Israel, Research Department, Jerusalem, Israel.

Feldmann, H. (2011). The unemployment effect of exchange rate volatility in industrial countries. Economic letters, 111(3), 268-271. 
Frenkel, R. (2006). Real exchange rate and employment in Argentina, Brazil, Chile and Mexico. Iktisat Isletme ve Finans, 19(223), 29-52.

Frenkel, R., \& Ros, J. (2006). Unemployment and the real exchange rate in Latin America. World Development, 34(4), 631646.

Gharavi Nakhjavani, S. A. (2002). Unemployment crisis in Iran's economy. Economic Research Review, 2(5), 171-184.

$\mathrm{He}, \mathrm{X}$. (2013). Real effective exchange rate and unemployment rate: The difference between re-exporting and non-reexporting countries (Unpublished master's thesis). Clemsan University, United States.

Lindblad, H., \& Sellin, P. (2008). The equilibrium rate of unemployment and the real exchange rate: An unobserved components system approach. Working Paper 152, Sveriges Riksbank.

Milas, C., \& Legrenzi, G. (2006). Non-linear real exchange rate effects in the UK labor market. Studies in Nonlinear Dynamics \& Econometrics, 10(1), 1-34.

Mohammadi, T., \& Gholami, A. (2008). An investigation into the effects of the policy of exchange rate unification on major variables of macroeconomic. Economic Questionnaire, 29, 49-74.

Mohammadi, T., \& Masjedi, F. (1997). Evaluation of the relationship between exchange rate and some macroeconomic variables in Iran. Journal of Planning \& Budget, 18, 57-93.

Nyahokwe, O., \& Ncwadi, R. (2013). Impact of exchange rate volatility on unemployment in South Africa. Mediterranean Journal of Social Sciences, 4(3), 109-120.

Pesaran, M. H., Schuermann, T., Treutler, B., \& Weiner, S. M. (2006). Macroeconomic dynamics and credit risk: A global perspective. Journal of Money Credit \& Banking, 38(5), 1211-1261.

Pesaran, M. H., Shin, Y., \& Smith, R. J. (2001). Bounds testing approaches to the analysis of level relationships. Journal of Applied Econometrics 16, 289-326.

Ranjbar, H., \& Moazen, S. (2009). An investigation into the relationship between exchange rate and other factors affecting unemployment in countries of the Organization of Islamic Cooperation (OIC). The Economic Journal, 3(6), $43-63$.

Shaari, M. S., Hussain, N. E., \& Abdul Rahim, H. (2013). The effects of oil price changes and exchange rate volatility on unemployment: Evidence from Malaysia. International Journal of Research in Business and Social Science, IJRBS, 2(4), 72-83.

Zhou, Y. (2010). Transmitted unemployment and exchange rate effect on labor market (Unpublished master's thesis). Lingnan University, Hong Kong. 